\title{
The Application Of Focused Ion Beam (FIB) On Biological Samples
}

\author{
H L Hing*, M A Kaswandi*, S. Normalawati*, A.Z. Sahalan* \& Y Muranaka** \\ *Department of Biomedical Science, Faculty of Allied Health Sciences, Universiti \\ Kebangsaan Malaysia, 50300 Kuala Lumpur, Malaysia \\ **Research Equipment Center, Hamamatsu University School of Medicine, Handayama, \\ Hamamatsu 431-3192, Japan
}

The focused ion beam (FIB) is a novel technique in electron microscopy that uses highenergy gallium ions to precisely and accurately sections or mill biological samples such as Helicobacter pylori cells, yeast cells and Polyalthia pollen spores irrespective of its place and location[1,2]. The step-by-step sectioning process will expose and reveal its internal structures, followed by observation with the FEG-SEM or conventional SEM for morphological comparison. The FIB also allowed a single cell to be sectioned at any desired position irrespective of its place and location. Some of the samples such as the pollen need no dehydration procedure.

Bacterial and yeast cells prepared on coverslips were fixed and dehydrated before coating them with osmium vapour while pollen spores were dusted to carbon stick stub and then osmium vapour coated. The bacterial and yeast cell samples for FIB need deposition with a layer of platinum $(20 \mathrm{~nm})$ to strength the cell structure. No deposition was required for the pollen spores. There was no collapse and destruction of cells when milled. The FIB-milled $H$. pylori(Fig 1-Fig 4), C. albicans(Fig $5 \& 6$ ) and pollen spores were then scanned with SEM and results obtained. Observation of FIB milled samples was also done at various angles. No much structural informations was obtained with the $H$. pylori milled samples. C. albicans milled samples showed many vesicles or inclusions bodies whereas the spore structure obtained after the spores were milled by FIB showed similarities in all three Polyalthia pollen spores(Fig $7 \& 8$ ). SEM observation of the spores also revealed three layer in the spore cut namely exine (outer layer), intine (central layer) and plasmalemma (inner layer). The result obtained showed that FIB could be used as an ultramicrotome in slicing the bacterial, yeast and pollen spores to observe the interior structure and for comparison purposes. In the case of the pollen spores, it also showed that external morphology but not internal structure of the pollen spores were important in species identification.

In conclusions, FIB can be used a micromaching tools for biological samples.

\section{References}

[1]. PR Munroe \& MR Dickson, Proc. 10 EMSM (2001) 8 - 11.

[2]. Y. Muranaka \& Y. Hotta, Proc.10 EMSM (2001) 12 - 18. 


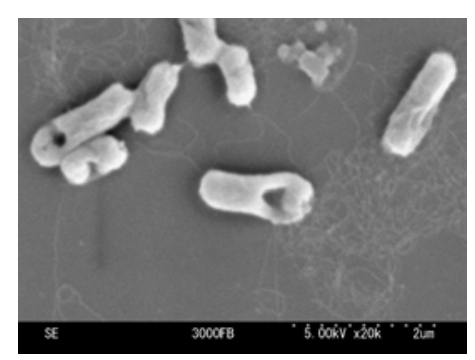

Fig 1:H. pylori before milling

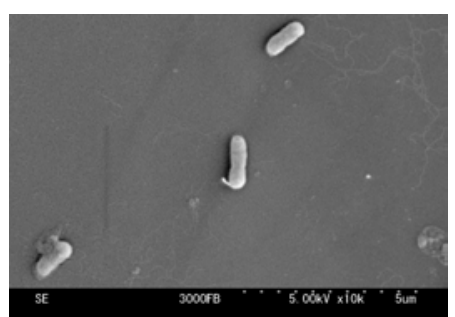

Fig 3:H. pylori before milling

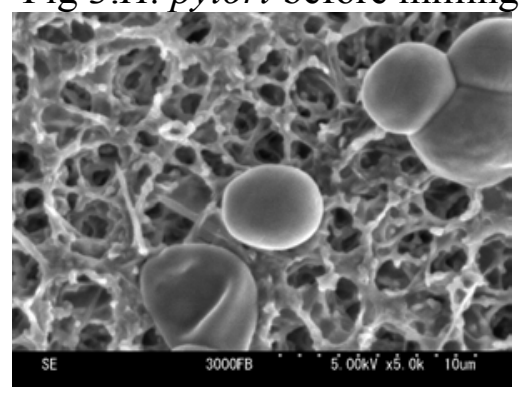

Fig 5: C. albicans before milling Fig 6: C. albicans after milling

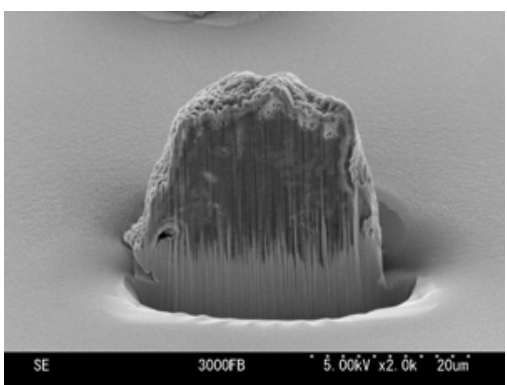

Fig 7: pollen spore after milling

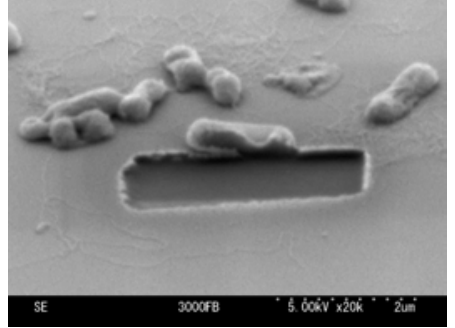

Fig 2: H. pylori after milling

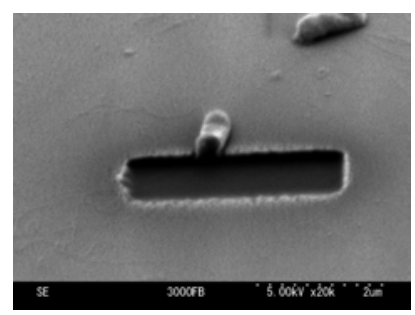

Fig 4: H. pylori after milling
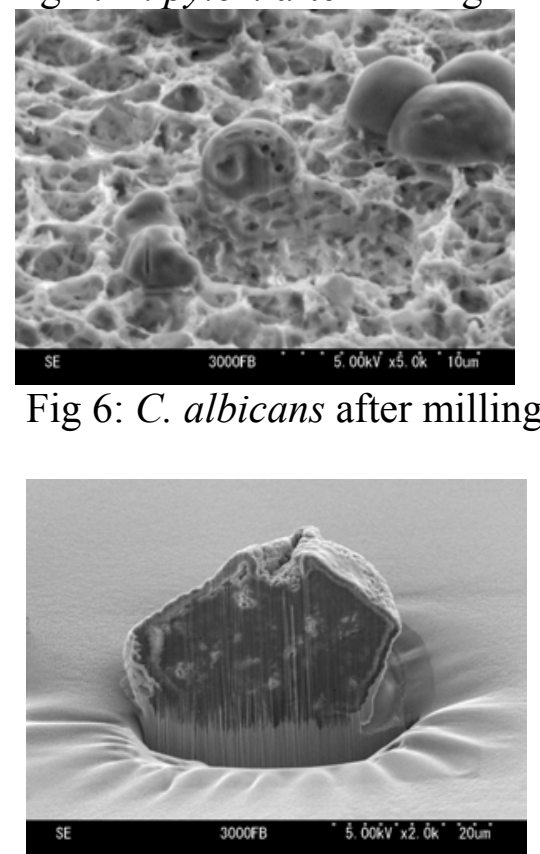

Fig 8: pollen spore after milling 